Robotics Camps, Clubs, and Competitions: Results from a U.S. Robotics Project

\author{
Gwen Nugent ${ }^{1}$ \\ Bradley Barker ${ }^{1}$ \\ Neal Grandgenett ${ }^{2}$ \\ Greg Welch ${ }^{1}$ \\ ${ }^{1}$ University of Nebraska-Lincoln \\ Lincoln, Nebraska, USA \\ ${ }^{2}$ University of Nebraska at Omaha \\ Omaha, Nebraska USA
}

Corresponding author:

Gwen Nugent, Corresponding Author

Nebraska Center for Research on Children, Youth, Families and Schools

University of Nebraska-Lincoln

216 Mabel Lee Hall

University of Nebraska-Lincoln

Lincoln, NE 68588

(402) 472-1009 gnugent@unl.edu 


\title{
Robotics Camps, Clubs, and Competitions: Results from a U.S. Robotics Project
}

\begin{abstract}
Funded by the U.S. National Science Foundation, the University of Nebraska-Lincoln has spent the last eight years developing and implementing a comprehensive educational robotics program for youth ages 9-14. The program was delivered in informal (out-of-school) learning environments through robotics camps, clubs, and competitions and provided robotics experiences to over 5,000 youth and 400 educators. The goal of the project was to positively impact the youths' science, technology, engineering, and mathematics (STEM) knowledge and attitudes - and to foster an interest in STEM careers. Results of extensive research and evaluation showed that youth participation in the robotics activities increased their STEM content knowledge (particularly engineering and computer programming), their perceived problem solving skills and their interest in engineering careers. Youth also perceived that the robotics activities were different from those in school, reporting that the robotics camp was more interesting and involved more hands-on activities.
\end{abstract}

Keywords: educational robotics, research, STEM knowledge, STEM interest

\section{Introduction}

Educational robotics represents a powerful, engaging tool for youth learning because they can touch and directly manipulate the robots, resulting in hands-on, minds-on, self-directed learning. Our robotics project was based on a theoretical framework derived from experiential learning, which is similar to problem-based learning in that students learn concepts and principles through authentic experiences and problems, typically in small groups, and with teachers as facilitators [1]. We also situate robotics within an integrated STEM framework, where youth must utilize science (inquiry), technology, engineering and mathematics skills to successfully complete the robotics activities.

Empirical support for educational robotics comes from research showing that robotics can increase learning in specific STEM concept areas [2], [3], [4]. Robotics also encourages student problem solving [5], [6], [7] and promotes cooperative learning [8], [9]. Beyond the potential to influence youth learning, educational robotics is a unique technology platform for increasing student interest in STEM. Internationally, many countries are investing in STEM educational programs to compete in the global marketplace and to increase the number of youth pursuing STEM careers [10]. Studies show that robotics can generate a high degree of student interest and engagement in math and science careers [11], [12].

This paper examines how our robotics program -- delivered through informal learning environments as summer camps, academic year clubs, and robotics competitions -- supports middle school youth STEM learning and motivation. Results are provided for three overarching areas of inquiry:

1. What is the impact of the robotics camps, clubs and competitions on middle school youth STEM knowledge, attitudes, and workplace skills?

2. What is the impact of the robotics experiences on youth career interests?

3. How do youth perceive the value of the individual STEM knowledge and skills gained during the robotics summer camps? How do the learning experiences compare to those they experience in school?

\section{Description of the Robotics Camps, Clubs, and Competitions}

At the heart of our robotics project is the curriculum, which consists of approximately 40 hours of instruction involving the building and programming of robots using the LEGO Mindstorms NXT robotics platform. The format of the activities involves a short introductory presentation by an informal educator followed by hands-on activities supported by structured worksheets. Participants typically work in self-selected, same-sex pairs to complete the majority of robotics tasks. Youth typically select friends or acquaintances as partners; educators assist as necessary to insure everyone has someone to work with. In addition, small groups of three or four students are formed for more advanced challenges. Individual lessons typically take one to two hours to complete; however more complex experiences can last as long as four hours. Sample lessons cover such skills as writing a simple program to display text on the brick, programming the robot motors for movement and various turns, using loops in a program, navigation to avoid obstacles using touch and ultrasonic sensors, and programming the sound sensor and the light sensor to track a line. (A complete description of the curriculum can be found in [13]; samples of the curriculum are on line at http://www.gt21.org). 
The camps and clubs utilize the same basic curriculum but educators are given the latitude to modify and adapt the instruction to meet the needs of their participants. The camps are delivered in the summer and typically last 40 hours (one week). The clubs, which usually meet during the academic year, vary considerably depending on the organizational sponsor (i.e. 4-H, after school). Some clubs meet the entire academic year, others only a couple of weeks. The longer time frame allows more in-depth exploration of individual topics, but individual sessions can be as long as a week apart, which causes more fragmented learning. Instructors often have to review and refocus youth before proceeding with the instruction. The club format is also more susceptible to having youth drop in and out or miss individual sessions.

The robotics competitions supported through the project are through the FIRST LEGO League, one of the largest educational robotics competitions with 16,000 teams competing internationally. The project began sponsoring competitions in 2010 , and the events have grown each year. The event is organized around a reallife science-based issue, with middle school participants assembling robots based on the LEGO Mindstorms kit to perform a set of defined tasks to address this issue. They also prepare an issue-based research project. Data from coaches has shown that team preparation typically lasts around 40 hours. The FIRST LEGO League does not have an official curriculum or coach training, but instead provides a handbook for coaches and links to external resources. To help support coaches in preparing youth for the competition, we made the project curriculum available. However, only about $20 \%$ of coaches reported using the project resources.

\section{Methodology}

\subsection{Participants}

Across the eight years of the project, we collected six years of data from 1825 campers, three years of data from 458 competition participants, and two years from 126 club participants. Camp participants represented a U. S. sample from 23 states, with approximately $70 \%$ male, $30 \%$ female. Competition participants, on the other hand, were concentrated in the Midwest; gender split was again $70 \%$ male, $30 \%$ female. The club data primarily came from Nebraska, but data was also collected from youth from seven states. In general, 67\% were males; 33\% female. Unlike the camps and competitions, the project has less control over club origination, organization, and research participation, and the numbers of club participants were considerably smaller than those for the other two formats.

\subsection{Instrumentation}

The instrumentation used in the camps and clubs each year was identical, with questions assessing STEM knowledge, attitudes, and workplace skills (Table 1). STEM content knowledge was measured through a multiple-choice assessment covering science (inquiry), mathematics (including fractions and ratios), computer programming (such as looping and conditional statements), engineering concepts and processes (such as gears and sensors), and engineering design. This instrument was modified over the years to be more application oriented and to rely less on factual recall. In addition, early versions of the instrument did not include questions on engineering design and science. The instrument's Cronbach alpha reliability was consistently around .82.

Table 1. Instrumentation

\begin{tabular}{|l|l|}
\hline \multicolumn{1}{|c|}{ Instrument } & \multicolumn{1}{c|}{ Outcome Measured } \\
\hline STEM cognitive assessment (multiple choice) & $\begin{array}{l}\text { Knowledge of science, computer programming, } \\
\text { engineering, and mathematics concepts and processes } \\
\text { related to robotics }\end{array}$ \\
\hline STEM attitudes (Likert scales) & $\begin{array}{l}\text { Task value: perceived value of science, mathematics } \\
\text { and robotics } \\
\text { Self-efficacy: confidence in performing robotics tasks } \\
\text { Workplace skills: teamwork and problem solving } \\
\text { Career orientation: interest in STEM careers }\end{array}$ \\
\hline
\end{tabular}

The attitudinal instrument [14] contains 33 items that utilize a Likert format ranging from (1) strongly disagree to (5) strongly agree. There are multiple scales, including youth perceived value (importance, usefulness) of mathematics, science, and robotics (e.g. "It is important for me to learn how to program a robot to carry out commands"), as well as their self-efficacy or confidence in performing robotics tasks (e.g. "I am confident I can program a robot to move forward two wheel turns (i.e. 720 degrees) and then stop)." The instrument also contains workplace skills questions focusing on youth use of teamwork (e.g. "I like being part of a team that is trying to solve a problem") and problem solving skills (e.g. "I make a plan before I start to solve a 
problem"). Unlike the cognitive instrument described above, this instrument was used consistently throughout the project, and showed high reliability as evidenced by a Cronbach alpha of .97. The final series of questions asked youth how interested they were in certain STEM-related careers. This section again used a Likert format ranging from $1=$ very uninterested to $5=$ very interested.

The competition instrumentation was similar to the one used in the camps and clubs, but was shortened because of the time constraints within a competition environment. Even with the fewer number of questions, however, the reliability was high, showing alphas of .80 for the knowledge test and .92 for the attitudinal survey.

Because our project was designed as an integrative STEM experience, we were interested in knowing how youth perceived the individual science, technology, engineering and mathematics content. Did youth view the camp primarily as a technology-oriented experience? Did they recognize that science and mathematics content was embedded within the curriculum? Did they believe what they learned in the summer camp would transfer into the school environment? To answer these questions, we developed nine generic Likert-type questions (5point scale) that could apply to each of the four STEM disciplines. For example, one question involved youth use of the separate skills to successfully complete the robotics activities, i.e. "I had to use ___ skills to successfully complete the robotics skills in this camp." The question appeared four times on the survey, with a different STEM area appearing in the blank. Other questions probed youth perceptions of a) the individual science, technology, engineering, and mathematics skills they learned during their robotics experiences, b) how this learning differed from what they experience in school, and c) how it helped them understand the impact of STEM on their personal life and the world. This last area was based on a contextual framework based on PISA Science 2006 [15].

\subsection{Data Analysis, Collection and Procedures}

The basic research design used throughout the project was a repeated measures, pre-post design, with dependent "t" tests examining differences between means at the two time points. Camp and club youth completed the preinstrumentation prior to participating in any robotics activities and completed the post instruments at the end of the respective camp or club experience. For the competition, pre instruments were distributed through the coaches as teams registered. Coaches were instructed to administer surveys before starting preparation for the competition. Post instruments were completed after youth had completed the competition activities on the day of the event.

An additional quasi-experimental study compared results from the summer camp to a control group composed of students identified by regional educational service units as youth with interest in technology and robotics [3]. This study used ANCOVAs, with pre-test scores serving as a covariate.

The student perception results addressing research question 3 were analyzed through a series of one-way, repeated measures ANOVAs to ascertain specific differences between each STEM discipline in terms of youth perception of their impact at various levels - in the robotics camp, school, their personal life, and society.

Separate analyses of the research data were conducted for each year of the camps, clubs, and competitions and many of these annual results have been published elsewhere $[3,13,14,16,17,18,19,20,21,22,23,24]$. This paper provides a synthesis of the research results, identifying data trends, and which reflect consistent and stable effects of the robotics experiences.

\section{Results}

Table 2 shows Cohen's d and eta squared $\left(\eta^{2}\right)$ effect sizes for the various youth outcomes by format by year. Discussion of the results is organized around the three guiding questions.

1. What is the impact of the camps, clubs and competitions on middle school youth STEM knowledge, attitudes, and workplace skills?

While the camp results are the most stable, results from all three formats reveal comparatively high effect sizes for the knowledge outcomes. (Cohen's rules of thumb for interpreting "d" effect sizes: a "small" effect size is .20, a "medium" effect size is .50, and a "large" effect size is .80; for $\eta^{2}$ "small" effect size is .02, "medium" is .13, and "large" is .26). Closer analyses of the individual scale scores show that the results were driven primarily by increases in knowledge of engineering and programming. Camps also resulted in the most consistent attitudinal results, with highest effect sizes for robotics self-efficacy. Self-efficacy also showed consistent increases in clubs. However, results for the youth perceived value and importance of STEM subject areas (task value) did not show consistent increases. The competitions and clubs had low effect sizes and the camps did not begin to show impacts until the last two years of data collection. An ongoing problem was the fact that the pre-test scores have been relatively high (over 4.0 on a five-point scale), making it difficult to 
realize increases. The possibility for increase is particularly problematic for the robotics scale, where youth tended to have even higher pre scores than other areas.

Table 2. Effects sizes for robotics camp, club, and competition research

\begin{tabular}{|c|c|c|c|c|c|c|c|c|c|c|c|}
\hline & & \multicolumn{5}{|c|}{ Camp } & \multicolumn{2}{|c|}{ Club } & \multicolumn{3}{|c|}{ Competition } \\
\hline Outcome & 2009 & $\begin{array}{l}2010 \\
\text { Pre- } \\
\text { post }\end{array}$ & $\begin{array}{l}2010 \\
\text { quasi- } \\
\text { exp. } \\
\eta^{2}\end{array}$ & 2011 & 2012 & 2013 & $\begin{array}{l}2011- \\
2012\end{array}$ & $\begin{array}{l}2012- \\
2013\end{array}$ & 2010 & 2011 & 2012 \\
\hline $\begin{array}{l}\text { Cognitive } \\
\text { overall }\end{array}$ & .60 & .72 & .27 & .51 & - - $^{*}$ & -- & .58 & .69 & .28 & .06 & -- \\
\hline Programming & .40 & .70 & .30 & .45 & .43 & -- & .50 & .96 & .40 & .09 & -- \\
\hline Engineering & .44 & .60 & .05 & .62 & .49 & .43 & .39 & .59 & .14 & .09 & -- \\
\hline Math & .49 & .12 & -- & .05 & .28 & -- & .01 & .06 & -- & -- & -- \\
\hline Eng. Design & -- & -- & -- & -- & .16 & .17 & .33 & .16 & -- & -- & -- \\
\hline Science & -- & -- & -- & -- & -- & .11 & -- & .25 & -- & -- & -- \\
\hline \multicolumn{12}{|l|}{ Task Value } \\
\hline Science & .15 & .10 & .00 & .20 & .14 & -- & .01 & -.09 & .20 & -.02 & .13 \\
\hline Math & .02 & .03 & .00 & .14 & .30 & -- & -.08 & -.08 & .17 & .06 & .17 \\
\hline Robotics & -.11 & -.06 & .01 & .16 & .38 & & -.05 & -.05 & -.02 & -.11 & .12 \\
\hline $\begin{array}{l}\text { Robotics self- } \\
\text { efficacy }\end{array}$ & .57 & .33 & .08 & .37 & .40 & -- & .04 & .36 & .22 & -.02 & .18 \\
\hline \multicolumn{12}{|l|}{ Workplace } \\
\hline Teamwork & -.47 & .03 & -- & .13 & .05 & -- & -.02 & -.02 & .00 & .11 & .38 \\
\hline $\begin{array}{l}\text { Problem } \\
\text { Approach }\end{array}$ & .12 & .31 & -- & .25 & .19 & -- & -.04 & -.04 & .30 & .17 & .43 \\
\hline \multicolumn{12}{|l|}{ Career } \\
\hline Scientist & .05 & .04 & -- & .14 & .08 & .16 & .05 & -.20 & -.06 & -.02 & .08 \\
\hline Engineer & .11 & .13 & -- & .20 & .01 & .09 & .08 & -.25 & -.08 & .16 & .21 \\
\hline Mathematician & -.08 & .18 & -- & .13 & .08 & .17 & .10 & -.16 & .06 & .15 & .11 \\
\hline Technologist & .09 & .01 & -- & .11 & -.01 & .13 & -.07 & -.41 & -.02 & -.19 & .07 \\
\hline
\end{tabular}

*Data not available

The problem approach scale from the workplace skills instrument also showed increases for two of the three formats (camps, competitions). In contrast, teamwork, which was emphasized in all formats and was particularly important in the robotics competitions, had low effect sizes, including several that were negative (representing pre-post decreases).

The quasi-experimental research comparing camp results from 2010 with those from a control group showed that the camp intervention led to significantly greater learning than a control group not receiving the instruction.

2. What is the impact of the robotics experiences on youth career interests?

The camp data is again more positive, particularly for engineering. In addition, there were increases in youth interest in engineering careers in two of the three years of competition data, but not in science, technology, or mathematics. The clubs did not show any increases in youth interest in pursuing STEM careers.

3. How do student perceive the value of the individual STEM knowledge and skills gained during the robotics summer camps? How do the learning experiences compare to those they experience in school?

Results are presented in graph form below. The means above the scale midpoint (3) in Figure 1 show that youth perceived that the STEM skills they learned during the camp helped them a) to be successful in completing the camp robotics activities, b) in understanding how STEM impacts society (the world they live in) and their personal life, and c) in helping them in school (average SD =1.09.) They also reported that they used technology and engineering skills more than science and mathematics, and they gained significantly more science, engineering, and technology knowledge than math to help them in school and in their personal life. However, even though the math skills were considered less useful, youth still rated the math knowledge gained as being helpful (3.56 to 4.00 on a 5-point scale). 


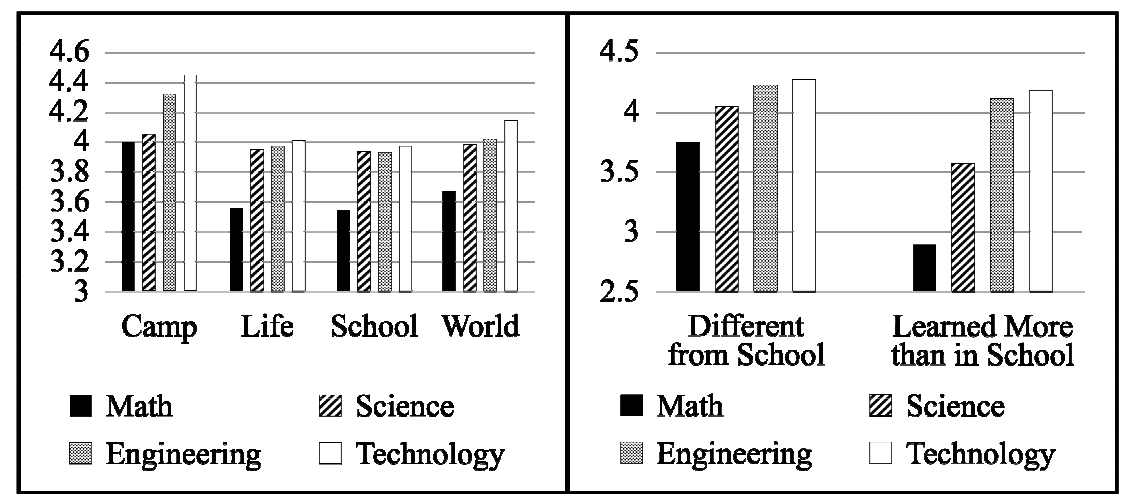

Fig. 1. Impacts of STEM skills learned in robotics camps

Fig. 2. STEM learning from camps vs. school

Results shown in Fig. 2 show that youth generally felt that all the STEM skills they learned were different from school $(3.75$ to 4.28 on a 5-point scale; average $\mathrm{SD}=1.08)$ and particularly the technology and engineering skills. Fig. 2 also shows dramatic differences between the four disciplines in terms of whether youth perceived that they learned more in the camp than in school. Engineering and technology were again rated significantly higher, with math having the lowest rating (average $\mathrm{SD}=1.20$ ). Looking at the data descriptively, there is one result which did not exceed the scale mid-point. Youth did not believe that they learned more math in camp than in school ( $\mathrm{M}=2.92$ on 5-point scale).

One question directly asked youth to assess their level of learning of each of the four STEM areas (1=none, $2=\mathrm{a}$ little, $3=$ some, and $4=\mathrm{a}$ lot $)$. Again, youth believed that they learned significantly more science $(\mathrm{M}=3.39)$, technology $(M=3.52)$, and engineering $(M=3.45)$ than math $(M=2.72)$.

In comparing the out-of-school learning environment to the in-school environment, youth also reported that the camp learning was more interesting $(\mathrm{M}=4.2$ on 5-point scale $)$ and involved more hands-on activities $(\mathrm{M}=$ 4.36).

\section{Discussion}

Results show that robotics summer camps, academic year clubs, and competitions promote STEM learning, particularly in terms of knowledge of engineering, engineering design, and programming. These results were found for both pre-post analyses, as well as the quasi-experimental study comparing summer camp results to a control group not receiving the robotics instruction. The higher scores for engineering and programming may reflect the lack of an engineering course in middle school and the unique technology skills required to program a LEGO robot. With no previous exposure to this specific content, it is not surprising that youth showed significant gains in knowledge in these two areas. Mathematics knowledge, on the other hand, did not show increases from participation in robotics clubs and competitions and limited increases in the camps. The student perception data also triangulates these results; youth reported learning about engineering and technology but they did not believe they learned a lot of mathematics from camp participation.

Consistent results were found for youth robotics self-efficacy, suggesting that participation in robotics camps, clubs, and competitions increases student self-confidence in performing robotics tasks. The self-efficacy results, which focused on student robotics performance, complement those from the knowledge assessment, which assessed basic knowledge. The self-efficacy increases reflect youth growing in self-efficacy as they gain experience in writing programs to effectively control their robot's actions.

A major goal of the robotics project was to increase student perceptions of the value and importance of science, technology, engineering and mathematics, with the hope that such attitudinal increases would translate into further STEM course taking and career interest. Our data has shown that most students enter the program with relatively high expressed interest, leaving little room for increases [13]. We did, however, begin to see some camp impacts during the last two years of data collection. The positive results in the later years of the project may be due to the fact that the camp format and curriculum were constantly being refined as we gained experience, and these results may reflect project formative improvement.

The careers data showed most success in increasing interest in engineering careers. We expect that the engineering increases are due the fact that youth are typically not exposed to any engineering curriculum in middle school and are unfamiliar with engineering both as a field of study and as a career. Thus, their experience with robotics design and the engineering process, coupled with explicit discussion of the 
responsibilities of an engineer as part of the curriculum, may have fostered both an increase in the knowledge of engineering, as well as in career interest. Interest in engineering careers also increased in two of the three years of competition data, but not in science, technology, or mathematics. Since there was no specific competition curriculum and no coach training, coaches focused on the requirements of the competition itself, with limited emphasis on educating youth about STEM careers. The lack of any significant results for the clubs may also be due to the variation in club format, with leaders having the option of picking and choosing the lessons. Thus, it is entirely possible that leaders omitted the lessons dealing with STEM careers in order to focus more on the hands-on robotics activities.

Regarding the workplace skills, consistent results were found for problem solving, which we believe is a result of the extensive troubleshooting necessary to control a robot. Informal observations showed that youth moved from using ineffective problem solving approaches, including trial and error, to a more plan oriented approach. Results across all three formats support the use of robotics as an excellent vehicle to promote more systematic problem solving in middle school youth.

In contrast, the lack of consistent increases in the teamwork scale may be due to the complex influences of peer relationships in middle school years and the variation in facilitator expertise in encouraging teamwork. More complete results of the camp teamwork results, including gender analyses, can be found in [14].

Finally, we know that the learning environment can shape the participant's experience and impacts, and our research showed that robotics summer camps, with their structured one-week format, resulted in the most potent impacts. However, the club format, despite its inconsistent length and youth participation, also showed positive increases in learning And despite the fact that increasing STEM learning is not an articulated goal of robotics competitions, our research showed positive learning impacts, as well as general attitude changes. Overall, the research results highlighted that despite the differences in goals, format, and curriculum, camps, competitions and clubs can all contribute to youth STEM learning and more positive STEM attitudes. Our research echoes other findings [25] showing that multiple formats can result in successful robotics programs, with positive impacts on youth.

\section{Acknowledgements}

This research was supported by the U.S. National Science Foundation (Grants \#0624591and \#833403).

\section{References}

1. Barrows, H. S. Problem-based Learning in Medicine and Beyond: A Brief Overview. New Directions for Teaching and Learning, 68, 85-9 (1996).

2. Barker, B., Ansorge, J. Robotics as Means to Increase Achievement Scores in an Informal Learning Environment. Journal of Research on Technology Education, 39, 229-243 (2007).

3. Nugent, G., Barker, B., Grandgenett, N., Adamchuk, V. Impact of Robotics and Geospatial Technologies Interventions on Youth STEM Learning and Attitudes. Journal of Research in Technology Education, 42, 391-408 (2010).

4. Williams, D., Ma, Y., Prejean, L., Ford, M. J. Acquisition of Physics Content Knowledge and Scientific Inquiry Skills in a Robotics Summer Camp. Journal of Research on Technology in Education, 40, 201-216 (2007).

5. Mauch, E. Using technological innovation to improve the problem solving skills of middle school students. The Clearing House, 75, 211-213 (2001)

6. Robinson, M. Robotics-driven Activities: Can They Improve Middle School Science Learning. Bulletin of Science, Technology \& Society, 25, 73-84 (2005).

7. Jojoa, E., Bravo, E., Cortes, E. Tool for Experimenting with Concepts of Mobile Robotics as Applied to Children's Education. IEEE Transactions on Education, 53, 88-95 (2010).

8. Beer, R., Hillel, J., Chiel, J., Drushel, R. Using Robotics to Teach Science and Engineering. Communications of the ACM, 42, 85 - 92 (1999).

9. Nourbakhsh, I. R., Crowley, K., Bhave, A., Hamner, E., Hsiu, T., Perez-Bergquist, A., et al. The Robotic Autonomy Mobile Robotics Course: Robot Design, Curriculum Design and Educational Assessment. Autonomous Robots, 18, 103-127 (2005).

10. Van Langen, A., Dekkers, H. Cross-national Differences in Participating in Tertiary Science, Technology Engineering and Math Education. Comparative Education, 41, 329-350 (2005).

11. Miller, D. P., Stein, C. So That's What Pi is for and Other Educational Epiphanies from Hands-on Robotics. In A. Druin \& J. Hendler (eds.) Robots for Kids: Exploring New Technologies for Learning Experiences. San Francisco: Morgan Kaufmann (2000).

12. Welch, A., Huffman, D. The Effect of Robotics Competitions on High School Students' Attitudes toward Science. School Science and Mathematics, 111, 416 - 424 (2011).

13. Nugent, G., Barker, B., \& Grandgenett, N. The Impact of Educational Robotics on Student STEM Learning, Attitudes and Workplace skills. In Barker, Nugent, Grandgenett, Adamchuk (eds.) Robotics in K-12 Education: A New Technology for Learning, pp. 94-119, Hershey, PA: IGI Global (2012). 
14. Nugent, G., Barker, B., Toland, M., Grandgenett, N., Adamchuk, V. Measuring the Impact of Robotics and Geospatial Technologies on Youth STEM Attitudes. In Bastiaens, Ebner (Eds). Proceedings of the World Conference on Educational Multimedia, Hypermedia, and Telecommunications, pp. 3331-3340, Cheasapeake, VA: AACE (2009).

15. Bybee, R. Advancing STEM Education: A 2020 Vision. Technology and Engineering Teacher, 70, 30 - 35 (2010)

16. Adamchuk, V., Barker, B., Nugent, G., Grandgenett, N., Patent-Nygren, M., Morgan, K., \& Lutz, C. Learning Geospatial Concepts as Part of a Non-formal Education Robotics Experience. In Barker, Nugent, Grandgenett, \& Adamchuk (Eds.), Robotics in K-12 education: A new technology for learning (pp. 284 - 301), Hershey, PA: IGI Global (2012).

17. Nugent, G., Barker, B., Welch, G., Grandgenett, N., Wu, C., \& Nelson, C. A Model of Factors Contributing to STEM Learning and Career Orientation. International Journal of Science Education. Advance online publication. doi:10.1080/09500693.2015.1017863 (2015).

18. Barker, B., Nugent, G., \& Grandgenett, N. Examining Fidelity of Program Implementation in a STEM-oriented Out-ofschool Setting. International Journal of Technology and Design Education, 24, 39 - 52 (2013).

19. Barker, B., Grandgenett, N., Nugent, G., \& Adamchuk, V. Pairing Educational Robotics with Geospatial Technologies in Informal Learning Environments. Journal of Youth Development, 5 (2). Available from http://data.memberclicks.com/site/nae4a/JYD_100502_finalx.pdf (2010)...

20. Barker, B., Grandgenett, N., Nugent, G., \& Adamchuk, V. Robots, GPS/GIS, and programming technologies: The Power of "Digital Manipulatives" in Youth Extension Experiences. Journal of Extension [online], 45 (5). Available from http://www.joe.org/joe/2010february/a7.php (2010).

21. Barker, B., Grandgenett, N., Nugent, G. A New Model of 4-H Volunteer Development in Science, Engineering, and Technology Programs. Journal of Extension, 47 (2). Available from http://www.joe.org/joe/2009april/iw4.php (2009).

22. Barker, B., Nugent, G., Grandgenett, N., \& Hampton, A. Examining 4-H robotics in the Learning of Science, Engineering and Technology Topics and the Related Student Attitudes. Journal of Youth Development: Bridging Research and Practice, 2 (3). Available from http://www.nae4ha.org/directory/jyd/jyd_article.aspx?id=f5a34e58-1cd3-4994-981db81fa406cd74 (2008).

23. Barker, B., Nugent, G., \& Grandgenett, N. Examining 4-H Robotics and Geospatial Technologies in the Learning of Science, Technology, and Mathematics Topics. Journal of Extension, 46 (3), www.joe.org/joe/2008june/rb7.shtml (2008).

24. Nugent, G., Barker, B., White, A., \& Grandgenett, N. (2011, June). The Impact of Robotics Competitions on Youth STEM Learning, Attitudes, and 21st Century Skills. In L. Cantoni \& C. McLoughlin (Eds.), Proceedings of the Ed Media 2011 World Conference on Educational Multimedia, Hypermedia and Telecommunications, Lisbon, Portugal (pp. 3614-3619). Chesapeake, VA: AACE.

25. Gomez, K., Bernstein, D., Zywica, J., Hamner, E. Building Technical Knowledge and Engagement in Robotics: an Examination of Two Out-of-school programs. In Barker, Nugent, Grandgenett, Adamchuk (eds.) Robotics in K-12 Education: A New Technology for Learning, pp. 94-119, Hershey, PA: IGI Global (2012). 
Gwen Nugent is Research Professor at the Nebraska Center for Research on Children, Youth, Families and Schools (CYFS) at the University of Nebraska-Lincoln. Dr. Nugent coordinates implementation and research projects focusing on the development and delivery of instruction and training to improve student learning and teacher competencies. She has over 30 years experience in the design and evaluation of mediated instruction and training and is currently a principal investigator and evaluator for grants funded by the U.S. National Science Foundation, Department of Education, and Department of Agriculture.

Bradley Barker is an Associate Professor and Youth Development Specialist with Nebraska 4-H. He spent 8 years with Nebraska Educational Telecommunications where he was an Interactive Media Producer. Currently, Dr. Barker is the Principal Investigator on a wearable technologies grant through the NSF ITEST program DRL \#1433822. Previously he served as PI on two National Science Foundation Grants to develop the Nebraska 4-H Robotics and GPS/GIS program and to scale-up the program to a national audience. Dr. Barker was also the PI on the National 4-H Robotics: Engineering for Today and Tomorrow curriculum development grant for National 4-H Council/CSREES.

Neal Grandgenett is the Dr. George and Sally Haddix Community Chair of STEM Education at the University of Nebraska at Omaha, where he coordinates the campus STEM priority and teaches courses in interdisciplinary STEM learning. He has authored over 130 STEM-related publications. He has evaluated more than 30 large grants for National Science Foundation, the U.S. Department of Education, the U.S. Department of Labor, NASA and various private foundations. Dr. Grandgenett is also a review editor for the Mathematics and Computer Education Journal (MACE).

Greg Welch is a Research Assistant Professor in the Nebraska Center for Research on Children, Youth, Families and Schools; serves as a core faculty member in the Nebraska Academy for Methodology, Analytics and Psychometrics (MAP), a methodological center housed within CYFS; and is the Director of the Bureau of Educational Research and Field Services, an applied research and evaluation entity focused on P-20 educational issues. Dr. Welch has significant experience providing methodological contributions to federally funded projects across a variety of disciplines. Dr. Welch's research focuses on evaluation and research methodology, structural equation modeling, assessment and measurement, and educational policy. 

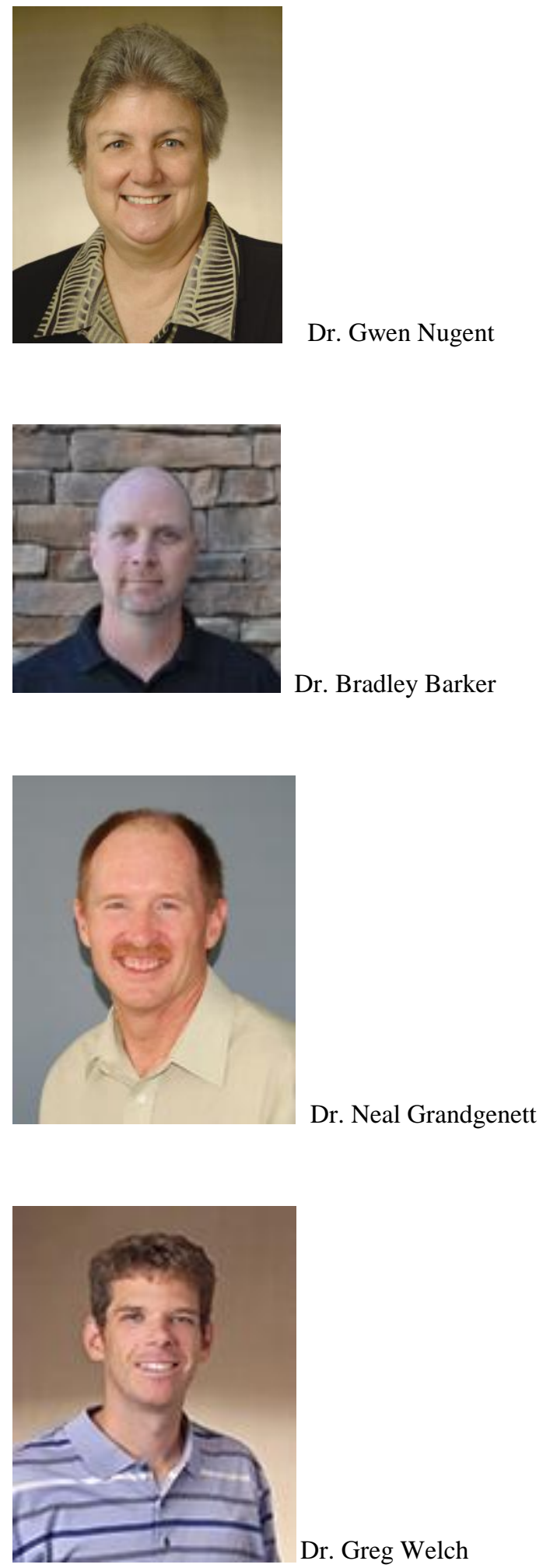